\title{
VALORIZAÇÃO DO TERRITÓRIO: UMA VIA PARA O DESIGN SUSTENTÁVEL NO MARANHÃO
}

\author{
VALUATION OF TERRITORY: A PATHWAY TO SUSTAINABLE DESIGN IN \\ MARANHÃO
}

\author{
Márcio James Soares Guimarães; Me. \\ Universidade Federal do Maranhão - UFMA \\ falecommg@gmail.com \\ André de Souza Lucca; Dr. \\ Universidade Federal do Maranhão - UFMA \\ aslucca@yahoo.com.br
}

\begin{abstract}
Resumo: Este artigo tem por objetivo articular uma reflexão sobre as relações existentes entre a Economia Ecológica, a teoria do Decrescimento e as ações do Design para o território, apresentando características para a atuação do designer como agente provocador de mudanças de comportamento e de práticas sustentáveis na produção artesanal no contexto maranhense.
\end{abstract}

Palavras-chave: economia ecológica; decrescimento, design para o território; práticas sustentáveis; produção artesanal.

\begin{abstract}
This article aims to articulate a reflection on the relationship between the Ecological Economics, the theory of degrowth and actions of Design for the territory, presenting features for the work of designer as agent provocateur behavior change and sustainable practices in production handmade in Maranhão context.
\end{abstract}

Keywords: ecological economics, degrowth; design for the territory; sustainable practices; artisanal production.

\section{DECRESCER QUANTITATIVAMENTE PARA CRESCER QUALITATIVAMENTE}

A preocupação com as questões ambientais e o aumento das restrições ecológicas no mercado internacional têm, de certa forma, forçado empresas a adotarem estratégias que permitam o desenvolvimento de produtos e modos de produção inovadores que minimizem os impactos e mantenham os benefícios econômicos. 
Na década de 1970, Herman Daly propôs a necessidade da defesa da transição da economia para um "estado estacionário", onde a escala de produção não excedesse a capacidade natural provida pelos ecossistemas (DALY e FARLEY, 2008). A condição estacionária proposta por Daly se alicerça sob a noção de que em determinado ponto o crescimento deixa de ser benéfico, comprometendo às gerações futuras o usufruto dos bens que a geração atual dispõe.

Georgescu-Roegen (2008), autor da Teoria Bioeconômica e um precursor dos estudos que demonstram a relação entre a lei de entropia e os processos econômicos, afirmou que uma economia em estado estacionário não seria suficiente, pois transmite a ideia de que a contenção do crescimento, seja ele populacional ou de consumo de energia e materiais, suplanta o processo entrópico. Segundo Georgescu-Roegen, o sistema econômico não pode existir indefinidamente, não seria realista imaginar a reciclagem total que promova a manutenção dos materiais, ainda que fosse possível o controle da quantidade consumida, e a produção contínua de bens. Como proposta de desenvolvimento, o autor sugere o estímulo às ações que podem contribuir para um desenvolvimento local, adequado às especificidades de cada território, processo que posteriormente fundamentaria o atual conceito de Decrescimento sereno e convivial por Latouche (2009).

Serge Latouche, professor de economia da Universidade Paris XI, expõe, em seu Pequeno Tratado do Decrescimento Sereno (2009), uma reflexão sobre o uso de práticas sustentáveis, sobretudo nas relações humanas e econômicas. Decrescer, para o autor, não evoca um crescimento negativo, mas o crescimento adequado às necessidades reais de um grupo ou comunidade, evitando desperdícios, fazendo uso mais efetivo de todo material/energia e demais potencialidades do local.

O Decrescimento é entendido como um conceito que permite agir na busca por modos mais sustentáveis de desenvolvimento, e pode ser entendido como conjunto de políticas democráticas e participativas que propõe uma desaceleração do ritmo econômico visando proporcionar melhor qualidade de vida através da adoção de medidas simples como: a relocalização das atividades produtivas, a restauração de práticas agrícolas camponesas, a troca de desempenhos de produtividade por reduções no tempo de trabalho gerando assim, mais postos de trabalho, dentre outras.

A proposta de Latouche (2009) sugere ainda, a adoção de oito passos capazes de reintroduzir a preocupação ecológica no meio social, político e cultural, são eles: reavaliar, que trata da substituição dos valores globais, individualistas e consumistas por valores locais, de cooperação, humanistas; reconceitualizar, que significa modificar as formas de conceitualização da humanidade, evidenciando a construção social considerando a pobreza e a escassez; reestruturar, ou seja, adaptar as estruturas econômicas e as relações sociais em função da nova escala de valores; realocar, que significa promover a autossuficiência visando suprir as necessidades prioritárias, minimizando o consumo e transporte, por exemplo; redistribuir, que diz respeito ao compartilhamento dos recursos naturais e à distribuição da riqueza; reduzir, que significa limitar o consumo à capacidade de carga da biosfera; reutilizar para evitar o desperdício, propor novo uso; reciclar e ampliar o tempo de vida dos produtos para evitar o consumo desnecessário. 
A implementação destas ações culmina num processo de desenvolvimento endógeno e sustentável, que adota a democracia como resposta à periferização ${ }^{1}$, a recuperação da autonomia local (autossuficiência alimentar, econômica e financeira) e a reintrodução da preocupação ecológica em todos os campos da vida humana. $E$, torna desejável que os modos de agir baseados em condutas especulativas, "que só visam lucros", sejam substituídos por uma postura sustentável, atrativa por valorizar os produtos por sua singularidade, por seus vínculos com a ambiência social e cultural de origem, e por valorizar as técnicas e materiais empregados em sua produção.

Quando se refere aos países emergentes, Latouche (2009) indica ainda a adoção de outros erres, complementares aos anteriores: romper, ou seja, desligar-se da dependência econômica e cultural aos países desenvolvidos; retomar a história interrompida pela colonização, pelo desenvolvimento e pela globalização; reencontrar e se reapropriar de uma identidade cultural própria; reintroduzir as ferramentas e produtos esquecidos ou abandonados por serem considerados ultrapassados ou obsoletos tecnologicamente; recuperar as técnicas e saberes tradicionais; e restituir a honra perdida, referindo-se aos países do terceiro mundo, propondo o a restituição de suas raízes identitárias de origem, aquelas que os distinguiam antes de sua colonização.

A efetividade dos resultados provenientes da realização destes passos, depende do protagonismo local, pois seu desenvolvimento é um fenômeno que resulta sobretudo das relações humanas, pela autonomia atribuída aos agentes locais e pelo aprofundamento da democracia participativa. Estes aspectos, consoantes à ideia de desenvolvimento territorial e de localização, já eram parcialmente preconizados, a partir dos anos 1970, por estudiosos do Design como proposta para a construção da sustentabilidade a partir de uma visão projetual².

A proposta aqui apresentada, de traçar um paralelo entre as ações propostas pelo Decrescimento, a Economia Ecológica e as ações de desenvolvimento do Design para o território parte da observação direta de situações vivenciadas pelo autor por meio de suas experiências e contribuições no planejamento de ações voltadas ao setor artesanal, compreendendo pequenos produtores que utilizam técnicas tradicionais de fabricação, seja na produção de artefatos artesanais, quanto na produção de produtos e subprodutos provenientes da agricultura familiar, e, enquanto pesquisa, é parte da fundamentação da dissertação de mestrado dirigida acerca da contribuição do Design para o desenvolvimento de práticas sustentáveis na produção artesanal.

\section{A PRODUÇÃO ARTESANAL E SUA VOCAÇÃO TERRITORIAL}

Segundo dados coletados pela Pesquisa de Informações Básicas Municipais (MUNIC 2006 apud Azevedo; Cavalcanti, 2013), realizada pelo Instituto Brasileiro de

1 A implantação de práticas democráticas estimularia a permanência do pequeno produtor em seu local de origem, evitando a migração e consequente periferização dos grandes centros urbanos.

2 Veja Tomás Maldonado, La speranza progettuale: ambiente e società. Turim: Einaudi, 1970; Victor Papanek, Design for the Real World: Human Ecology and Social Change, Nova York, Pantheon Books, 1971; Gui Bonsiepe, Diseño industrial, tecnología e dependencia. México, D.F.: Edicol, 1978; Gui Bonsiepe, El Diseño de la Periferia. Debates y experiencias. Barcelona: Gustavo Gili, 1982 
Geografia e Estatística - IBGE em parceria com o Ministério da Cultura, 64,3\% dos municípios brasileiros possuem algum tipo de produção artesanal. Desta forma, o artesanato tem grande importância econômica, é, em muitos casos, a principal fonte de ocupação e renda de populações com baixa escolaridade e qualificação, configurando-se também, por sua vocação de transferência contínua de conhecimento, como alternativa para a fixação do artesão à sua região de origem, evitando o êxodo rural.

A produção artesanal é fruto do acúmulo de saberes transmitidos por gerações. Os artífices são herdeiros e detentores de um conhecimento tácito de inúmeras técnicas de extração e manipulação das mais diversas matérias-primas que sob sua expertise, são transformadas em artefatos cuja inspiração exprime os valores e a visão de mundo destes artistas, criando assim, representações de sua identidade cultural, como expõem Cavalcanti, Andrade e Silva (2009):

\footnotetext{
"Os artefatos revelam hábitos, valores, conhecimentos, conceitos e necessidades que analisadas em conjunto permitem compreender o processo da evolução da humanidade. Como testemunhas silenciosas de uma civilização, os artefatos representam sua cultura, não apenas material, mas também aspectos da cultura imaterial como os modos de fazer, as formas de organização e gestão do que se produz". (CAVALCANTI; ANDRADE; SILVA, 2009)
}

No intuito de manter vivo este saber, instituições de fomento ${ }^{3}$ e de pesquisa têm se dedicado ao exercício do planejamento de ações que possibilitem a permanência do artesanato, tanto por seu valor cultural, quanto por sua capacidade de ocupação e geração de renda. Estas instituições surgiram a partir da preocupação com a questão dos bens materiais culturais, assunto intensamente analisado e discutido pelo Instituto do Patrimônio Histórico e Artístico Nacional - IPHAN, que iniciou a formulação de agentes públicos que determinam políticas públicas, financiam e fomentam a produção artesanal por meio de programas com abrangência nacional, responsáveis pelo desenvolvimento de ações voltadas ao aproveitamento das vocações regionais e à preservação das culturas locais.

A autonomia econômica, defendida pelo Decrescimento e a Economia Ecológica, tem sido objetivo das ações de desenvolvimento do setor artesanal. Almejase que os artesãos, após participar de intervenções proporcionadas por instituições de fomento, tenham aptidão a lidar com o mercado de forma autossuficiente, através da promoção e integração de iniciativas relacionadas ao artesanato e da troca de experiências e aprimoramento na gestão de processos e produtos artesanais, desejando assim, que a promoção destas medidas contribuam para a melhoria da competitividade do produto artesanal e despertem a capacidade empreendedora do produtor, possibilitando uma maior inserção do artesanato brasileiro nos mercados nacionais e internacionais.

3 Instituições que se dedicam no apoio ao artesanato, com a finalidade de identificá-lo, classificá-lo e promovê-lo. 


\section{EXPERIÊNCIAS LOCAIS: OPORTUNIDADES PARA O DESIGN SUSTENTÁVEL}

Espontaneamente, algumas experiências coerentes à proposta de Latouche, vêm sendo desenvolvidas por comunidades locais no Maranhão. Em Pequi da Rampa, comunidade quilombola oriunda do século XIX, pertencente ao município de Vargem Grande, a agricultura desenvolvida por meio de técnicas artesanais tem sido o foco da tomada de atitudes que lhe elevaram ao patamar de principal atividade econômica local.

A formação de duas associações, a Associação Comunitária do Povoado do Pequi da Rampa e a Associação de Mulheres Negras do Povoado Pequi, permitiram, por meio de ações articuladas junto a entidades e ao poder público, o alcance dos meios necessários à produção agrícola e à transformação da comunidade num polo de produção sustentável.

Atualmente, parte da colheita é destinada à comercialização e outra é destinada ao consumo dos moradores. Entre os principais produtos comercializados estão: as farinhas branca e d'água, conhecidas regionalmente como farinhas seca e de puba, respectivamente. Os recursos obtidos pela comercialização são empregados conforme as decisões tomadas nas assembleias comunitárias, das quais todos fazem parte.

Além da agricultura e extrativismo, Pequi da Rampa destaca-se por suas manifestações culturais, especialmente por sua devoção religiosa que reúne, nos meses de maio e dezembro, um grande número de fiéis participantes e pelas apresentações de seu "tambor de crioula", oriundo dos tempos de escravidão. Nestes eventos surgem outras oportunidades de aproveitamento da produção na obtenção de recursos: doces, compotas, geleias e produtos fitoterápicos são comercializados.

Também em São Luís, capital do Estado, um grupo de mulheres provenientes das comunidades das Vilas Primavera, Sarney e Industrial, tem se destacado pelas características inovadoras adotadas em sua produção artesanal. $\mathrm{O}$ grupo Mulheres de Fibra em poucos anos se transformou de um encontro esporádico de artesãs, que se reuniam para compartilhar técnicas de trabalho, numa associação consolidada, denominada Associação Buriti Arte, especializada na produção de artigos artesanais feitos da fibra do buriti.
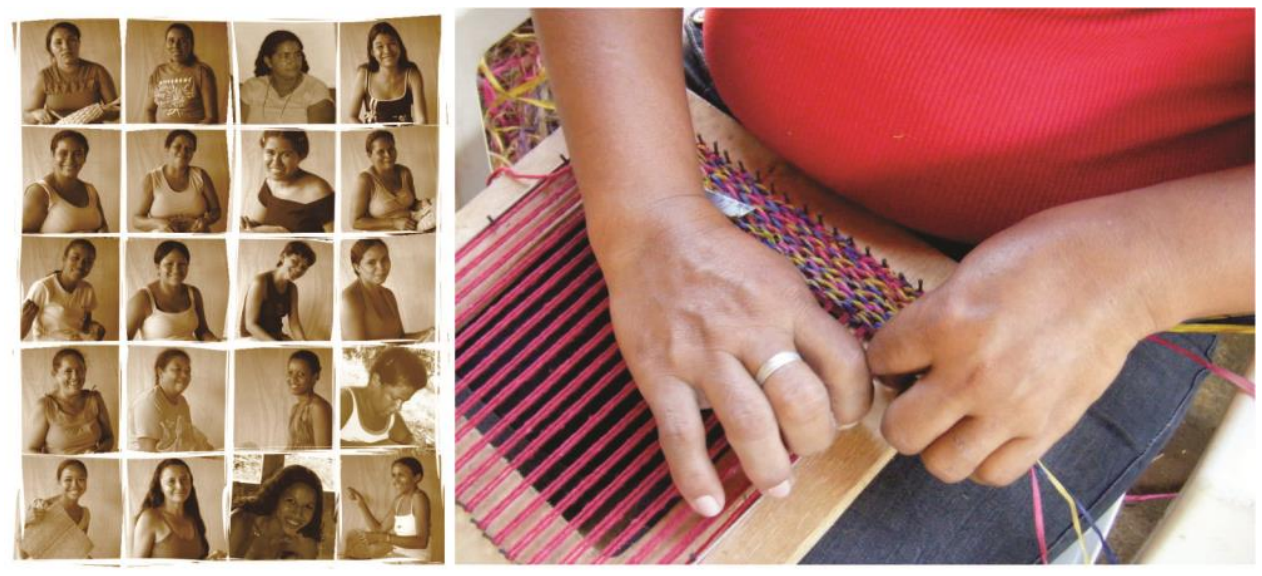

Figura 01 - Artesãs e tecelagem de fibra com auxílio de bastidor de madeira.

Fonte: elaborada pelo autor, com base na pesquisa realizada. 
Esta mudança só se tornou possível, em ambos os casos, a partir da eleição de representantes que defendessem os interesses do grupo e contatassem entidades e órgãos públicos de apoio ao setor artesanal, para que numa ação conjunta, fossem eleitas as diretrizes que norteariam a produção e o desenvolvimento do grupo. $O$ trabalho, orientado pelo Serviço de Apoio às Micro e Pequenas Empresas - SEBRAE, compreendeu as fases de planejamento, orientação, educação ambiental, educação em gestão, melhoria da qualidade do produto, comunicação e ações de mercado.

No âmbito Europeu, observam-se experiências inovadoras provenientes da GrãBretanha, Irlanda e países vizinhos, onde pequenas comunidades se dedicam ao compartilhamento de iniciativas a fim de minimizar seus impactos ambientais Tais ações, conhecidas como Cidades em Transição (Transition Towns), têm como base os pensamentos desenvolvidos a partir da ideia do desenvolvimento da autonomia, da resiliência local e na tomada de atitudes que se contrapõem ao crescimento nãoeconômico incessantemente praticado pelos países desenvolvidos e em desenvolvimento.

De acordo com Lucca (2012), o Design para o território nasce e se desenvolve em situações nas quais a cooperação e a colaboração são partes fundamentais para a concretização das mudanças. Neste contexto, o Design para o território, um conjunto de ações de design que buscam a promoção do produto local, tem contribuído para a qualidade e a valorização da origem e dos processos adotados na fabricação destes produtos, auxiliando na representação de sua condição de produto ligado ao território e à sociedade que o produziu.

Os projetos elaborados para estas comunidades consideram o uso dos recursos em favor da promoção da autonomia e da resiliência local, da ocupação da mão de obra e da geração e manutenção dos recursos econômicos no território. Em Pequi da Rampa a prática da organização de sistemas de troca, compartilhamento e cooperação possibilitou a transparência e melhor aplicabilidade de recursos.

Verificou-se ainda que, ao contrário de outras associações também beneficiadas, o resultado obtido nestas comunidades se deve à resposta dada pelos participantes, pois o processo de desenvolvimento, como apontado anteriormente, se dá de "dentro para fora". Foi necessário fortalecer a autonomia aos agentes locais para que as mudanças políticas, econômicas e sociais desejadas acontecessem, dentre elas, o acesso ao processo de desenvolvimento do território.

\section{VALORIZAÇÃO DO TERRITÓRIO, UMA ESTRATÉGIA PARA PROJETOS SUSTENTÁVEIS}

O design orientado para a valorização territorial, baseado na sustentabilidade, proporciona a atuação do designer como mediador e agente que pode auxiliar a definir formas mais adequadas de planejamento, produção, apresentação e comercialização dos produtos, atendendo às necessidades do produtor e do mercado. Conforme Krucken (2009), as contribuições do design para a valorização de produtos locais podem ser agrupadas em três linhas de trabalho: na promoção da qualidade dos produtos, dos territórios e dos processos de fabricação; no apoio a comunicação, 
aproximando o mercado e intensificando as relações territoriais; e no apoio ao desenvolvimento de arranjos produtivos e cadeias produtivas sustentáveis, as "cadeias de valor".

Para Thackara (2008), "oitenta por cento do impacto ambiental exercido pelos produtos, serviços e infraestruturas em nosso redor são determinados na fase projetual". Assim, os designers têm papel fundamental no processo de formulação de produtos e serviços sustentáveis, pois o processo de concepção de um projeto thes permite a realização de uma intervenção prévia em relação aos possíveis impactos desses produtos, através da incorporação dos requisitos ambientais desde início do desenvolvimento do projeto, como fora exposto por Manzini e Vezzoli (2005), que afirmam que para um produto ser considerado eco eficiente, deve, sobretudo, apresentar a minimização de recursos (redução no uso de materiais e de energia) e a seleção de recursos e processos de baixo impacto ou processos e fontes energéticas de maior eco compatibilidade.

Seguindo este preceito de produto eco eficiente, Thierry Kazazian (2005), baseado em estudo desenvolvido para o Manual Promise do PNUMA (1996), estabelece uma reflexão acerca das atitudes que devem ser tomadas a cada fase de vida do produto. São elas: escolha de materiais de menor impacto; reduções de massa e volume; fabricação limpa; otimização dos sistemas de embalagem e distribuição; redução dos impactos durante a utilização; otimização da duração de vida; otimização do fim da vida, valorização e a adoção de um novo conceito e uma nova resposta às expectativas dos usuários, em um ciclo contínuo.

Também Thackara (2008), ao abordar o "design em um mundo complexo", aprofunda estes conceitos acrescentando aos mesmos a necessidade de uma mudança de paradigma no que se refere ao projeto em design: deixa-se de "projetar para" para "projetar com", assim como, se altera a visão do "design como um projeto" para o "design como um serviço", reforçando, desta forma, a ideia apontada por Morin (2000) que alerta para a necessidade iminente de que o desenvolvimento não seja somente material, mas que também se dê de forma intelectual, afetiva e moral, para que atinja toda a humanidade.

A partir desta nova postura, compete ao designer, atuar junto a equipes multidisciplinares, colaborando na elaboração de práticas sustentáveis, que resultem em benefícios de igual abrangência nas quatro dimensões da sustentabilidade: social, (inclusão social, autoestima do trabalhador, proteção e promoção das condições de saúde humana etc.), político-institucional (democracia participativa, cidadania, combate à pobreza etc.), econômica (mudança de padrões de consumo, distribuição equilibrada de recursos e investimentos etc.) e ambiental (promoção do desenvolvimento sustentável dos assentamentos humanos, despoluição de fontes, e rios, redução da pegada de carbono etc.).

\section{CONCLUSÃO}

As ideias apresentadas neste texto têm a finalidade de contribuir para a reflexão sobre as relações existentes entre os resultados propostos pela Economia Ecológica, a teoria do Decrescimento e as ações de Design para o território. A Economia Ecológica contribui para fundamentar a discussão acerca de uma mudança 
de paradigma: a viabilidade de um mercado honesto, que assume a verdade ecológica e suas consequências, culminando na criação de uma economia global.

A teoria do Decrescimento contribui para a proposição de uma análise realista da situação atual, sugerindo a adoção de tomadas de decisões (os oito "erres") que possibilitarão a inovação política e a autonomia econômica, o protagonismo dos pequenos negócios como soluções à crise ecológica. As experiências locais corroboram este princípio, pois se apresentam como exemplos de que as formações de pequenos grupos resultam em mudanças significativas de gestão em busca do bem comum, resultando em benefícios para todos os envolvidos. O artesanato, a permacultura e a agricultura familiar, enquanto meios de produção local, devem ser considerados como exemplos viáveis de implantação dos conceitos propostos pelos autores que referenciaram este texto, pois, em parte, já são iminentemente impulsionados pela cooperação e uso mínimo de recursos, privilegiando o uso de matérias-primas locais.

Portanto, a abordagem do Design para o território, quando aplicada no contexto do Maranhão, poderá orientar a ação dos designers na construção de um desenvolvimento local e sustentável apto a configurar-se como um passo coerente na implantação de políticas de desenvolvimento e inovação. O aprofundamento desse estudo mostra-se pertinente enquanto fundamentação teórica para a construção de procedimentos de diagnose, estratégias projetuais e critérios de avaliação que permitam a realização de projetos de design adequados às necessidades da população brasileira, contribuindo, assim, para a formação de uma base de dados que o auxilie o planejamento do uso de recursos e o reconhecimento de elementos que representam e valorizam as culturas locais presentes em cada região do Brasil.

\section{NOTA}

A discussão levantada neste artigo é parte da fundamentação da dissertação de mestrado em Design intitulada "Contribuições do design para o desenvolvimento sustentável da produção artesanal", trabalho orientado pelo Prof. Ph.D. José Evandro R. Guimarães.

\section{REFERÊNCIAS}

AZEVEDO, Lucyana. CAVALCANTI, Virgínia. A relação entre o design e os Programas de Fomento ao Artesanato Brasileiro. Disponível em: www.acasa.org.br. Acesso em 28 ago. 2013.

CAVALCANTI, Virgínia Pereira; ANDRADE, Ana Maria de; SILVA, Germannya D’Garcia Araújo. Design, sustentabilidade e artesanato: reflexões e práticas metodológicas. In: Design e sustentabilidade. Cadernos de estudos avançados em Design, Dijon De Moraes e Lia Krucken (org). Barbacena, MG: Ed.UEMG, 2009.

DALY, H. e FARLEY, J. Economia Ecológica: Princípios e Aplicações. Lisboa: Instituto Piaget, 2008.

GEORGESCU-ROEGEN, Nicholas. O decrescimento Entropia, Ecologia, Economia. São Paulo: SENAC, 2008. 
KAZAZIAN, T. Haverá a Idade das Coisas Leves: design e desenvolvimento sustentável. São Paulo: Senac, 2005.

KRUCKEN, Lia. Design e Território: valorização de identidades e produtos locais. São Paulo: Studio Nobel, 2009.

LAKATOS, E. M.; MARCONI, M. A. Metodologia Científica. 2a edição. São Paulo: Atlas 1995.

LATOUCHE, Serge. Pequeno Tratado do Decrescimento Sereno. São Paulo: Editora WMF, 2009.

LUCCA, André de Souza. Design Participativo para a Valorização da Produção do Território. In: $10^{\circ}$ CONGRESSO BRASILEIRO DE PESQUISA E DESENVOLVIMENTO EM DESIGN - P\&D DESIGN, 2012, São Luís. Anais. São Luís: UFMA, 2012.

MANZINI, Ezio. Design para a inovação social e sustentabilidade: comunidades criativas, organizações colaborativas e novas redes projetuais. Rio de Janeiro: e-Papers, 2008.

MANZINI, E.; VEZZOLI, C. O desenvolvimento de produtos sustentáveis. Os requisitos ambientais dos produtos industriais. São Paulo: EDUSP, 2005.

MORIN, Edgard. Introdução ao pensamento complexo. Porto Alegre: Sulina, 2000.

ORGANIZAÇÃO DAS NAÇÕES UNIDAS PARA A EDUCAÇÃO, A CIÊNCIA E CULTURA UNESCO (1997). Final Report - International Symposium on Crafts and International Markets. Manila, Filipinas: Ed. WTO.

SACHS, Ignacy. Primeiras Intervenções. In: Dilemas e desafios do desenvolvimento sustentável no Brasil. Elimar Pinheiro do Nascimento e João Nildo Vianna. (org.). Rio de Janeiro: Garamond, 2009.

THACKARA, J. Plano B: $\mathbf{O}$ design e as alternativas viáveis em um mundo complexo. São Paulo: Saraiva, 2008. 